\title{
Una lectura de la migración de venezolanos a Colombia a través de los memes que circulan en redes sociales: revanchismo y representaciones perversas ${ }^{1}$
}

\section{A review of Venezuelan migration to Colombia through memes on social media: revanchism and perverse representations}

Recibido: 06/08/2020

Aceptado: 09/11/2020

Publicado: 30/11/2020
Sandra Marcela Lobo Ojeda sandralobo@usantotomas.edu.co https://orcid.org/0000-0003-4837-4207 Universidad Santo Tomás (Colombia)

Juan Carlos Córdoba Laguna juan.cordoba@utadeo.edu.co http://orcid.org/0000-0003-3777-2410 Universidad Jorge Tadeo Lozano (Colombia)

Álvaro Lizarralde Díaz consultor.alvarolizarralde@tallercreativoaleida.com.co https://orcid.org/0000-0001-9113-0326 Taller Creativo de Comunicación Aleida Sánchez (Colombia)

Alexánder Torres Sanmiguel alexandertorres@usantotomas.edu.co http://orcid.org/0000-0002-1880-4352 Universidad Santo Tomás (Colombia) Lozano (Colombia). 
Resumen: El presente artículo es el resultado de una investigación que analizó la incidencia de la migración venezolana en los imaginarios que los colombianos tienen de los migrantes y de sí mismos, así como de la coyuntura sociopolítica actual de los dos países, expresados a través de "memes" que circulan en redes sociales, las cuales son tomadas como escenarios activos de la esfera política que permiten observar las variaciones de la opinión pública. Metodológicamente, la investigación se enmarcó dentro del enfoque mixto (cualitativo-cuantitativo) a partir del análisis del discurso de un conjunto de memes extraídos de Facebook y Twitter, cuyos resultados preliminares se pusieron en contraste con los de encuestas y grupos focales dirigidos a ciudadanos colombianos, con la finalidad de identificar los tipos de imaginarios en torno a la migración venezolana y sus incidencias en la imagen que los colombianos tienen de su propia realidad y del migrante.

Palabras clave: Imaginarios, Migración, Colombia, Venezuela, Redes sociales.

Abstract: This article is the result of an investigation that analyzed the incidence of Venezuelan migration in the imaginary that Colombians have of migrants and of themselves, as well as of the current socio-political situation of the two countries, expressed through "memes" that circulate on social networks, which are taken as active scenarios of the political sphere that allow observing the variations in public opinion. Methodologically, the research was framed within the mixed approach (qualitative-quantitative), based on the analysis of the discourse of a set of memes extracted from Facebook and Twitter, whose preliminary results were contrasted with those of surveys and focus groups directed at Colombian citizens to identify types of imaginaries around Venezuelan migration and its impact on the image that Colombians have of their own reality and of the migrant.

Key words: Imaginaries, Migration, Colombia, Venezuela, Social Networks.

\section{Introducción}

La política venezolana y las condiciones de vida del pueblo venezolano siempre han sido de interés para los colombianos, por el hecho mismo de com- 
partir una extensa frontera, una historia común y una cultura e idiosincrasia similares. Con el inicio de la llamada "revolución bolivariana" (en el primer gobierno de Hugo Chávez) el proceso de migración de ciudadanos venezolanos hacia Colombia se ha incrementado. De acuerdo con Pineda \& Ávila (2019), se pueden identificar como mínimo tres grandes éxodos de venezolanos en los últimos veinte años: a) el primero de estos, especialmente entre 2002 y 2003, con la salida de los empresarios y grupos económicos como Polar o Farmatodo, huyendo de la inseguridad y atraídos por la globalización, las circunstancias tributarias de su país y las formas de inversión y mercados en otras partes del mundo; b) el segundo, particularmente entre 2006 y 2007, al iniciar el segundo período presidencial de Chávez, el de altos ejecutivos y profesionales capacitados, ante la dificultad cada vez más evidente de oportunidades laborales e incorporación al sistema productivo; y c) el último, generado a partir del año 2013, por el deterioro de las condiciones sociales y la crisis humanitaria. Este último éxodo "destaca particularmente la migración de personas pertenecientes a los sectores con menos recursos económicos y formación académica, lo cuales probablemente en otras condiciones no se habrían planteado migrar" (Pineda \& Ávila, 2019, p. 57).

En Colombia es interesante observar cómo la migración de venezolanos ha transformado las ideas y creencias sobre la realidad nacional y sobre el colombiano mismo, así como también sobre Venezuela y sus nacionales, propiciando formas de circulación de la información en las cuales las redes sociales y el uso de memes hacen evidente tanto los imaginarios sobre el "otro" como sobre los propios colombianos, porque (por primera vez en toda su historia) Colombia vive un proceso de recepción de migrantes (de inmensas proporciones) provenientes de Venezuela.

Durante el 2014, ingresaron 80,261 venezolanos a Colombia y para 2018, la cifra de migrantes ascendió a 865,015, lo cual indica un incremento del $1077 \%$ en tan solo cuatro años (FEDESARROLLO, 2018, p. 4). En mayo de 2020, el Ministerio de Relaciones Exteriores de Colombia (2020) estima que la cantidad de migrantes venezolanos en el país ascendería a 1'764,000. Se trata de un fenómeno cuyo estudio y ponderación son recientes.

Dadas las transformaciones en la esfera política y la centralidad de las redes sociales digitales en la divulgación de propaganda política, acercarse a los contenidos expresados por la ciudadanía en las redes sociales a través de 
memes da cuenta de las tensiones por el significado en términos de opinión pública.

El meme (como unidad de sentido autocontenida) debe su trascendencia a su posibilidad de replicabilidad, propagabilidad o viralización, dando cuenta no sólo del punto de vista de su creador o productor, sino de toda una red de comunidades de sentido que se ven identificadas, afectadas o intimidadas por su mensaje, lo que permite observar que (desde un punto de vista comunicativo) podemos separarlo y aislarlo en su manifestación y análisis, pero (desde un punto de vista interpretativo) el meme convoca otros conocimientos, ideas, discursos y expresiones culturales e históricas significativas, compartidas intersubjetivamente a partir de procesos de apropiación y reinterpretación en sus variables psicosociales, dando cuenta de procesos de sentido mucho más amplios y complejos, en los que es posible rastrear imaginarios y representaciones sociales que aluden a ese carácter mimético de la realidad contenido en el meme como estrategia comunicativa.

Así pues, la investigación se propuso el siguiente objetivo general: determinar la forma o modo en que la migración venezolana ha propiciado la formación de imaginarios sobre los migrantes y sobre los colombianos mismos, así como sobre la coyuntura sociopolítica colombiana y venezolana, a través del análisis de memes que circulan en las redes sociales. De forma específica, se quiso describir la relación entre el contexto sociopolítico colombo-venezolano y la producción de memes sobre la migración. En segunda instancia, analizar el mensaje de los memes que circulan en Facebook y Twitter frente al tema de la migración venezolana. En tercer lugar, identificar la relación entre los memes y la dimensión del imaginario que refuerzan; y, finalmente, analizar la recepción y circulación de estas formas de expresión en la red.

Desde una perspectiva teórica, este artículo propone un breve recorrido conceptual alrededor de las nociones de imaginarios sociales y de memética como categorías de análisis, para dar soporte a las conclusiones.

\section{Imaginarios: el lado fantasioso de las ideas}

Para comprender cómo los colombianos leen el fenómeno de la migración masiva venezolana -y en esa lectura generan imaginarios no solo sobre los 
venezolanos, sino también sobre sí mismos y sobre la situación colombiana-, es importante revisar algunos enfoques desde los cuales se ha entendido el concepto de "imaginario".

Los imaginarios sociales han sido abordados desde diferentes visiones teóricas: antropológica, con Durand (1979); desde el psicoanálisis, con Castoriadis (2007); desde una perspectiva económica, con Marx (2012); desde la semiótica, con Dittus (2006); desde una visión filosófica, con Maffesoli (1987) y Althusser (1988), entre otros autores. El concepto de imaginario para esta investigación se centró particularmente en la visión de Althusser (1988), Castoriadis (2007), Martín Barbero (1987) y Dittus (2006).

Para la sociología alemana de finales del siglo XIX y comienzos del siglo $\mathrm{XX}$, el imaginario es producto de una estructura determinada por elementos materiales, pero en la que la realidad es estimulada por factores como la fantasía y los deseos, en el que las ideas encarnan la base sobre la que se apoya la vida real. Marx (2012) plantea que la vida material es la que determina las representaciones y las ideas: todo cuanto el hombre piensa e imagina es producto de su comportamiento material y no al revés, como lo vislumbró el idealismo hegeliano.

Alejándose de la propuesta de Marx, hacia una ideología amarrada a una clase social, Lenin (1997) propone que es el grupo el que elabora la realidad social, en la que está incluido lo político. Sin embargo, se mantiene la propuesta marxista de la ideología como parte de la superestructura definida por características económicas. Desde este enfoque, el imaginario es sinónimo de "ilusión", pero no por ello deja de establecerse una conexión a partir de la superestructura entre lo económico y lo que está fuera de esta esfera, puente que es utilizado para formar ideas y representaciones aceptadas en las sociedades.

Lo anterior se relaciona más con cómo el sistema les sugiere a los sujetos lo que tienen que pensar sobre una situación, lo cual constituye una intervención privilegiada en la construcción de ese imaginario. Para el caso concreto de la migración masiva venezolana, esta situación ha sido aprovechada como tema en las agendas de candidatos en campañas políticas para mostrar promesas o riesgos de lo que le sucederá al país, de no ser apoyadas las propuestas por ellos realizadas. 
Para Althusser (1988), la ideología es una representación deformada imaginariamente que el individuo hace de su contacto con el mundo y no una correspondencia del sujeto con su realidad. El imaginario es el producto del control profesado por los aparatos ideológicos, lo cual puede ser una ilusión resultado de la arbitrariedad existente, lo que hace ver la imaginación como falseamiento. Esta influencia sucede de forma desapercibida y se evidencia cuando el sujeto actúa en relación con su conciencia.

Dicho esto, la ideología resulta ser una representación determinada del mundo (religiosa, moral, etc.), cuya deformación imaginaria depende de su relación (también imaginaria) con sus condiciones de existencia, es decir, en última instancia, con las relaciones de producción y de clase ("ideología" = "relación imaginaria con las relaciones reales"). Esta relación está dotada de existencia material (Althusser, 1988, p. 25).

En el caso de la migración, se puede inferir que la forma como una parte de los colombianos evalúa el fenómeno migratorio venezolano no es producto del cotejo de datos o de la indagación sobre el hecho. Por el contrario, sus apreciaciones tienden a ser reproducciones de lo expuesto por otros, tales como medios de comunicación y personajes principalmente políticos, con sesgos ideológicos y objetivos claros.

Por su parte, Castoriadis (2007) vislumbra que el imaginario acompaña la existencia del individuo y le posibilita a este hacer enlaces con la realidad, situándolo de una forma coherente con su pasado y presente, ya sea por substitución o por comparación, con el uso de redes simbólicas, las cuales necesitan al imaginario para su existencia y representación. Este autor utiliza el concepto de "instituciones imaginarias" para referirse a aquellas que logran explicar lo que lo racional no consigue. Asimismo, muestra cómo el sujeto desarrolla un equilibrio entre la necesidad y la satisfacción con lo social, en el que imaginario es sinónimo de capacidad inherente de creación que le permite al sujeto identificarse de manera simbólica con necesidades y objetos que desembocan en la creación.

Lo imaginario del que hablo no es imagen de. Es creación incesante y esencialmente indeterminada (histórico-social y psíquica) de figuras/ formas/imágenes, a partir de las cuales solamente puede tratarse de "alguna cosa". Lo que llamamos "realidad" y "racionalidad" son obras de ello. (Castoriadis, 2007, p. 12) 
Según Castoriadis (2007), cuando el sistema consigue interferir, o hasta controlar el imaginario, se da la alienación, lo que trae como consecuencia la pérdida en el individuo de autoconocimiento propio y de su entorno y posibilita a este ser una herramienta que interfiere en la visión del sujeto sobre situaciones coyunturales.

La migración masiva venezolana ha afectado drásticamente el imaginario que los colombianos tenían del país vecino y de sus habitantes: se transitó de la visión de una Venezuela que en las décadas de los 70 y 80 tenía una población con poder económico gracias al petróleo, a la cual los colombianos migraban para realizar trabajos domésticos, a una nación de la cual (en el siglo XXI) emigran sus ciudadanos al no responder a sus necesidades básicas, situación que invierte roles, abre el espacio para nuevas visiones y elabora imaginarios con tendencia a homogenizarse entre una porción de colombianos no acostumbrados a recibir migración extranjera.

Así, los imaginarios sobre la migración se visualizan en prácticas socioculturales, las cuales son capaces de superar la realidad para superponerse a ella. En tales imaginarios, lo popular se instala, convirtiéndose es un espacio de intersección de variadas construcciones de sentido e interpretaciones de la realidad. Para Martín Barbero (1987), lo popular está presente en manifestaciones del cotidiano social, como canciones, chistes, narraciones, etc. Y en la actualidad, también en los memes. En efecto, los memes de colombianos sobre la migración de venezolanos son un ejemplo de lo popular actuando sobre una situación cotidiana, presentada como un "problema", el cual se convierte en un terreno que estimula la creación, pero también permite visualizar los alcances de la violencia simbólica ejercida por los individuos en estas prácticas comunicativas.

En una posición semejante a la de Martín Barbero (1987), Dittus (2006) afirma que en los imaginarios lo simbólico es un elemento constitutivo de la realidad, en la que una referenciación continua de una situación (resultado de un proceso comunicativo mediático, conflictivo y saturado) es la base para la elaboración de sentido, de significados sociales y de apropiaciones, las cuales pueden traducirse en manifestaciones violentas, pero, a la vez, se elabora un punto de referencia temporal, como ha sucedido con la constante llegada de venezolanos. El producto del anterior proceso es una estructura de categorías que sirve para denominar una situación real o sugerida, que 
presenta diferentes matices y donde la unión de esta con el imaginario determina reglas generales de interacción social, vistas como lógicas por los individuos, pero que aun así no eliminan la posibilidad de recomposiciones en la lectura de las situaciones que suceden y que pueden incorporarse al cotidiano.

En la construcción del imaginario sobre la migración venezolana a Colombia, lo evidente ya no es tan evidente. Existen imágenes que se mantienen como referentes de realidad, que son usadas frente a la coyuntura de la migración masiva en la que pueden existir o no coterminales comunicativas que las robustecen. $\mathrm{O}$, al contrario, se crean nuevas imágenes resultado de un alto o bajo nivel de interacción comunicativa, principalmente entre individuos del mismo entorno, quienes comparten códigos comportamentales y discursivos, con los cuales construyen sentidos que pueden mover de posición referentes socioculturales y alterar el discurso identitario tradicional establecido, debido a que los nuevos datos le dificultan al individuo reconocerlo.

La avalancha de datos que los colombianos reciben sobre la migración venezolana muestra una actividad comunicativa con una variedad de versiones compartidas (cuando no contradictorias) de lo que sucede. Hablar de lo imaginario supera el concepto de imaginación e implica de forma dinámica definir, significar, regularizar un hecho con el uso de referentes de todo tipo: mediáticos, narrativos, históricos, de memoria. "Los imaginarios sociales actúan como sustento de conservación, cambio y filtro de una realidad significante multidimensional"'2 (Dittus, 2006, p. 172).

Es en la amplitud del cotidiano donde adquiere validez el imaginario, el cual actúa sobre una situación concreta, en un contexto específico, pero cambiante, al igual que lo hacen las representaciones construidas colectivamente, las cuales reelaboran la realidad haciéndola multidimensional y median en los niveles de sociabilidad de los individuos, como sucede con la migración venezolana y la forma de ser expresada en las redes sociales como manifestación de la opinión pública a través de memes.

2. Se trata del quinto argumento de la teoría de los imaginarios sociales de Dittus (2006). 


\section{Memes: la "perversa" economía comunicativa}

El hecho de que los venezolanos escojan a Colombia como su destino hace presuponer que los migrantes asumen la situación de Colombia como mejor respecto de la de su país y alienta instantáneamente también el supuesto entre los colombianos de que su país está en mejores condiciones que su vecino. Las redes sociales han ido dando cuenta de tal hecho, con memes y mensajes de toda índole, a través de los cuales se ha configurado un nuevo imaginario acerca de uno y otro país.

El meme es una unidad comunicativa de uso frecuente en comunidades y territorios digitales y que está representada por un conjunto de signos o sistemas de significación, tanto visuales como escritos, que entran en fusión en la producción de sentido, generalmente a través de recursos retóricos como la ironía, el sarcasmo o la burla, los cuales permiten transitar por expresiones que van desde la convergencia hasta la disidencia de puntos de vista frente a temas y personajes de interés y relevancia dentro del acontecer nacional y la opinión pública.

La producción de sentido sobre la coyuntura sociopolítica en Colombia (a partir de la llegada masiva de migrantes venezolanos) se ve reflejada en las redes sociales que se convierten hoy en expresión de opiniones diversas y en tensión por la construcción de la opinión pública. De allí la pertinencia de comprender sus nuevos códigos y lenguajes. En este caso, se parte de entender que las representaciones elaboradas en las redes sociales con el uso de memes son manifestaciones en las cuales emergen percepciones e imaginarios sobre "el otro", pero también sobre los propios colombianos. Por esto la trascendencia de intentar comprender la lógica de las formas de producción, circulación e impacto de este tipo de contenidos en la actualidad.

Siguiendo autores como Blom y Pinker (citados en Lull \& Neiva, 2011), Shifman (2013), Wiggins \& Bowers (2015), se continúa con una tradición que se atribuye a Richard Dawkins, en su obra El gen egoísta (1976), acerca de ciertas unidades de cultura infecciosas (que se transmiten de persona a persona, como los virus en la vida orgánica) que explicarían los logros evolutivos de la especie en el largo plazo. En ese sentido, Dawkins introduce el término "meme" como un modo de conceptualizar (si no de explicar completamente) la presencia, proliferación y atracción de ciertos temas y rasgos culturales. 
Se trata de un asunto profundo: ¿por qué algunas ideas culturales inspiran una perdurable y extendida aceptación y utilidad? Dibujando ilustrativos paralelos entre la replicación genética y la transmisión cultural, Dawkins especula cómo las ideas culturales podrían establecer y mantener su influencia. (Lull \& Neiva, 2011, p. 27)

Desde la aparición de esta obra, muchos científicos, intelectuales y gente común utilizan la expresión "meme" para referir la rápida circulación de fenómenos culturales contenidos en breves descriptores de enorme propagación, sobre todo a través (desde hace algunos años) de las redes sociales. En el meme hace presencia (con una economía comunicativa) una actividad de selección, contagio y diseminación de ideas que invaden y se acumulan en la mente de las personas: "El meme es un breve, pegajoso y práctico descriptor de una idea enorme y difícil de manejar" (Lull \& Neiva, 2011, p. 28). El meme concentra un proceso de almacenamiento de contenidos compactos por imitación social, que ha permitido a los humanos el aprendizaje y transmisión cultural. El aprender copiando nos ha posibilitado a los humanos formas complejas de reconocimiento, modos superiores de pensamiento y maneras para asegurar la difusión, circulación y progresión de la herencia cultural.

La actuación del meme lleva consigo la concentración en una unidad de significado social compartido de instrucciones y pautas de acción e interpretación en la transmisión de la cultura. Puede entenderse (en la forma de tránsito del meme) una existencia psicológica al habitar las mentes de los individuos, pero también una existencia social más allá de los sujetos, donde su permanencia (independiente de sus huéspedes) depende del lugar de las ideas que expresa y su posición en la cultura. De esta forma, a la circulación del meme subyace un principio de selección y filtro que pasa por la capacidad de imitar como destreza comunicativa. La mejor imitación en cuanto representación de la idea sobrevive, ligando la comunicación a los principios de la selección natural y primacía del más fuerte y apto (Dawkins, 1989).

No obstante, esta capacidad imitativa (que en gran medida debe lograr contenidos sintéticos, breves y fáciles de interpretar para poder atraer y llegar al mayor número de personas para su reproducción) depende, a su vez, de la necesidad social de expresar ideas complejas, que en muchas circunstancias atañen, cuestionan o critican las representaciones e ideas que se asientan en la tradición, la hegemonía o el poder, haciéndolo de modo indirecto, soterrado, 
a través de la ironía, el sarcasmo, el chiste o el humor en general. De esta manera, los contenidos expuestos por los memes dan cuenta de las prelaciones culturales, estableciendo en su selección de temas las prioridades pragmáticas discursivas de la agenda social que en sí mismas perfilan los rasgos de la transmisión y la herencia cultural.

En el caso de la presente investigación, el flujo de memes sobre la coyuntura sociopolítica colombo-venezolana da cuenta de los principales aspectos expresados por la población para observar dicha crisis. Por esto se puede entender la insistencia en temas como la salud, el empleo o la alimentación, que surgen en las redes sociales de forma recurrente a través de memes que cuestionan el nivel de vida colombiano, así como del vecino país.

Los memes (para su expresión y difusión) apelan y necesitan del conocimiento de las pautas, patrones o rasgos culturales. Por eso pueden usar como recurso una expresión microscópica o minúscula de la cultura (un sonido, un color, una imagen, un gesto, etc.) que por contingencia (metonimia) refieren a un grupo social o a una persona en particular, así como a valores o prácticas pródigamente aceptadas o, por el contrario, ampliamente rechazadas.

De manera general, un meme (como una unidad compacta de significación y conocimiento) opera en articulación, relación y dependencia de otras formas de conocimiento y significación, en conexión con otras ideas, representaciones, memes o conocimientos que tienen lugar en la cultura, pero que (para su circulación y difusión) requieren de personas que tienen un conocimiento limitado o particular de la cultura, del contexto y de la realidad.

El hecho histórico de que (por primera vez) Colombia sea un país receptor de migrantes extranjeros de esta magnitud, genera y transforma las ideas que se tienen sobre la situación del propio país y estas representaciones e imaginarios se hacen evidentes en el contenido expresado y expuesto en los memes, que utilizan expresiones arraigadas en la cultura como el deporte, el folklore, la gastronomía, la farándula o sus exponentes, para lograr condensar, comprimir y expresar ideas que, después de su origen (dependiendo de su capacidad de contagio y circulación) se convierten en manifestaciones de la cognición social, de la opinión pública y de la cultura. Así se evidencia en los memes seleccionados para esta investigación, en los que aparecen figuras del atletismo (Caterine Ibargüen, Yulimar Rojas, Usain Bolt), actrices (Amparo Grisales) 
o personajes ficticios (Jerry, el ratón de la conocida caricatura). Los memes utilizan estos personajes en los montajes con la finalidad de exaltar al colombiano o desprestigiar al venezolano.

A través del anterior recurso, se logra tanta efectividad en la forma de propagación y circulación de la información, que en la sociedad actual se habla de la metáfora del "virus" o la "viralización", para entender y explicar las formas de expansión, divulgación y difusión de ciertos contenidos e informaciones en la red. Sin embargo, esta analogía pasa por alto una diferencia fundamental entre biología y cultura: en términos biológicos (por definición) los virus son agentes patógenos que invaden (en muchos casos de forma agresiva) las células del cuerpo, deteriorando su salud al causar diversas enfermedades. En este caso, el organismo es un agente pasivo sin más resistencia o filtro que sus anticuerpos o defensas. Sin embargo, la dispersión o transmisión de ideas para la preservación de la cultura implica individuos conscientes, capaces de reflexión y discernimiento sobre el bien y el mal, así sea dentro de un sistema de creencias controversial.

El hombre es, entre los animales, el único dominado por la cultura, por influencias aprehendidas y transmitidas de una generación a otra. Algunos afirmarán que la cultura es tan importante, que los genes, sean egoístas o no, son virtualmente irrelevantes para comprender la naturaleza humana. (Dawkins, 1989, p. 51)

Asimismo, la propagación de ideas que soporta la cultura en los seres humanos lleva un curso vertiginoso que (a diferencia del resto de animales) no se adapta a los rigores de la naturaleza y su determinismo biológico, sino que opera con su inteligencia sobre esta, transformándola. La cultura es ese arsenal de conocimiento que (en un período relativamente corto de la historia) nos ha dado la ciencia, la tecnología, las instituciones, la democracia, etc., aprovechando y alterando la naturaleza y lo que esta nos ofrece.

Lo que esta nueva forma de expansión, circulación, divulgación del conocimiento y la información en la red implica (más allá de la forma o limitación de la metáfora o la analogía utilizada para su comprensión) es repensar y redireccionar teorías hegemónicas sobre la transmisión e influencia cultural, como el imperialismo cultural ("teoría crítica") o "la colonización ideológica", que de alguna manera se encuentran pensados y responden a la forma de 
operar de los medios de comunicación tradicionales (prensa impresa, radio y televisión), pero no para las nuevas formas de la comunicación en la sociedad de la información.

En este sentido, expresiones como "público", “audiencia”, "receptor" y "espectador" se encuentran limitadas para entender y analizar una comunicación con otras verticalidades, formas de participación y transmisión, que abren paso a expresiones y conceptos como "prosumidor" o "interactor" (Lull \& Neiva, 2011) y a teorías como la imitación social (Dawkins, 1989), de la cual se desprende la expresión "meme" por mimesis (interpretación) o teorías como la del "contagio social" (Christakis \& Fowler, 2010).

Es pertinente superar la metáfora de la "viralización", rescatando del pensamiento darwinista (alrededor de la comunicación) un principio de selección de las ideas en la transmisión de la cultura que hoy en las redes sociales y en la sociedad de la información es poco claro, débil o difuso, para entender la expansión y sobrevivencia de una idea contenida; por ejemplo, en un meme. En el caso de esta investigación, es importante la reflexión en torno a la selección, permanencia o transformación de una serie de ideas sobre lo nacional expresadas a través de memes que encuentran eco o acogida en la medida misma de su circulación como revelación o enunciación discursiva de una realidad. El meme es una manifestación ideológica cuya divulgación da cuenta de los contenidos y temas relevantes que (por más complejos que sean) no pasan inadvertidos para los prosumidores o interactores de estos territorios digitales en los que se mueve ahora la información y la ciudadanía.

Autores como Shifman (2013) atribuyen a los memes algunas características de relevancia para su análisis dentro de la cultura digital. La primera característica para analizar los memes es entenderlos como "información cultural" que pasa de persona a persona y gradualmente se transforma en un fenómeno social compartido. Esto se constata en todas las plataformas para socializar contenido elaborado por usuarios para usuarios, como YouTube, Twitter, Facebook, Wikipedia y otras similares. De esta forma, dada la multiplicidad de rutas que puede tomar la información, la descentralización y la no jerarquización entre usuarios que permiten estas plataformas, un contenido difundido por un individuo puede alcanzar niveles masivos en pocas horas, lo que, a su vez, estimula nuevas formas de ser y hacer con los medios y nuevas mentalidades e identidades. 
Una segunda característica de los memes tiene que ver con su forma de reproducción por imitación o mímesis. Desde la oralidad, pasando por la escritura y toda la era de la imagen, la capacidad de copiar, emular, repetir o duplicar se encuentra ligada a nuestra necesidad de presentar y representar la realidad. Plataformas como YouTube se encuentran plagadas de imitaciones y copias de artistas de buenas a malas, transformándose incluso en indicadores de éxito por el número de seguidores que determinarían su nivel de emulación. Sumado a esto se encuentra una serie de aplicaciones de fácil acceso para que los usuarios puedan descargar, remezclar, reeditar y redistribuir contenidos de forma simple.

El término "meme" es particularmente adecuado para describir este exceso de reelaboraciones, ya que el concepto (que connota deliberadamente "mimesis") es lo suficientemente flexible como para capturar una amplia gama de intenciones y acciones comunicativas, que abarcan desde copia ingenua a imitación despectiva. (Shifman, 2013, pág. 365)

La imitación, la reedición, el remix y la remezcla (Wiggin \& Bowers, 2015), cercanos a la parodia, la suplantación y el plagio, se convierten en pilares fundamentales de una cultura contemporánea marcada por la hipersimulación y el simulacro (Baudrillard, 2000), que ponen en duda o cuestionan la originalidad y la creatividad de estos días, en los que la imagen y la apariencia, es decir, el "hacer parecer" de las cosas y las personas, es más importante que el ser o el hacer de los mismos.

Un tercer atributo de los memes se encuentra ligado a su circulación, difusión o divulgación, que dependen de un proceso sistemático de selección, filtro y competencia comunicativa por la elección de la mejor representación. Según Hofstadter:

Los memes, como los genes, son susceptibles de variación o distorsión, el análogo de la mutación. Varias mutaciones de un meme tendrán que competir entre sí, así como con otros memes, por la atención; es decir, por los recursos del cerebro en términos de espacio y tiempo dedicado a ese meme. (citado en Wiggin \& Bowers, 2015, p. 5)

El rango de impacto, la amplitud física espacio-temporal de la expansión, la extensión y el nivel de contagio determinan el grado de adaptación al contexto 
sociocultural en el que se desarrollan y propagan los contenidos ideológicos miméticos. La web proporciona un escenario de investigación y experimentación en el que las huellas digitales que dejamos todos los usuarios se transforman en la nueva minería, a través del análisis de metadatos, en el que los expertos e investigadores tienen la capacidad de rastrear la evolución y expansión de los memes para comprender sus formas de operar y sus impactos sociales.

En este orden, la Internet y las redes sociales se encuentran inundadas de contenido mimético susceptible de investigación y análisis, convirtiéndose en un buen espacio que da cuenta de las lógicas y transformaciones de la cultura, los imaginarios sociales y las variaciones y tensiones de la opinión pública frente a hechos, personajes y situaciones coyunturales o de crisis, como es el caso de la migración de venezolanos a Colombia y todas las manifestaciones y expresiones ciudadanas que encontramos en las redes sociales que, a su vez, son un reflejo del colombiano mismo.

La transmisión y difusión de memes manifiesta una serie de sentimientos y posturas que pueden ir de la inclusión, el apoyo y la solidaridad con la situación social del migrante, a su rechazo y estigmatización como amenaza, siendo, además, evidencia de las tensiones e imaginarios dentro de la opinión pública respecto del tema. Sin embargo, la decisión de circular cierto tipo de contenido o información (y con quiénes) depende, en gran medida, de la postura ideológica de cada individuo producida dentro de sus grupos sociales de referencia y la intención que busque producir con el mensaje en la construcción de su propia identidad.

Para muchos, la red se ha transformado en un súper organismo (Christakis \& Fowler, 2010) que pareciera actuar con conciencia y vida propia, aunado a un poder de control, manipulación e influencia que puede restringir, o por lo menos afectar, las elecciones en cualquier ámbito, limitar la individualidad y cuestionar la propia libertad. Desde otro ángulo, para otros la red encierra un potencial de interconexión capaz de trascender individualidades y, por tanto, de trascenderse a sí mismo y las limitaciones e intereses egoístas; un poder de comunicación con los demás suficiente para coordinar metas, realizar obras y lograr cambios que los individuos por separado jamás alcanzarían; una interconectividad que puede facilitar la comprensión del otro y su diversidad, para avanzar en su reconocimiento, ampliar la experiencia de la democracia y poder mejorar como humanidad. 


\section{Metodología}

Para analizar y comprender el fenómeno de la migración a través de los memes, se propuso una metodología de investigación mixta, fundamentada en los enfoques cualitativo y cuantitativo. Desde una perspectiva cualitativa, los métodos utilizados se pueden enmarcar en el análisis semiótico de los mensajes, para lo cual se identificaron, recolectaron y seleccionaron memes en las redes sociales Facebook y Twitter, a los que se les aplicó una matriz de análisis para hacer una lectura e interpretación de estos. Los memes circularon en un período comprendido entre enero de 2016 y diciembre de 2018.

Desde lo cuantitativo, se aplicó una encuesta online $e^{3}$ dirigida a dos grupos de ciudadanos: los primeros, de 18 a 30 años; y los segundos, de 31 años en adelante. El objetivo fue identificar diferentes tipos de imaginarios en torno a la migración venezolana. Para el análisis de los resultados se clasificaron las respuestas de las personas en un rango de edad de 18-30 años y de 31 años en adelante. La razón de esta clasificación estuvo determinada por la experiencia frente a la realidad venezolana y la hipótesis de que las personas menores de 31 años, en su mayoría, no conocen la historia de este país, y saben poco acerca de la época en que los colombianos migraban a Venezuela o se abastecían de los productos que entraban por la frontera. Su único referente sobre el venezolano es el que tienen producto de la situación actual de migración y deterioro social del país, contraria a la de las personas mayores de 31 años, que podrían tener más información sobre la Venezuela anterior a la llegada de Chávez al poder.

Se realizó una encuesta a 65 personas vía online, todas mayores de 18 años y de uno y otro género, con nivel de educación desde básica primaria hasta postgrado. Posteriormente, para triangular datos y contrastar los resultados preliminares del análisis semiótico de los memes con las opiniones más detalladas de ciudadanos colombianos, como trabajo de campo se realizaron dos grupos focales, con las mismas categorizaciones etáreas de la encuesta: un grupo focal con personas de 18 a 30 años, y otro con personas de 31 a 65 años.

3. La encuesta y sus resultados se pueden ver en el siguiente link: https://docs.google.com/forms/d/ 1YETlEOFNyZBaZhhi_pN2TUnxjUObwRZEoJCsbKzduEI/edit\#responses 
El grupo de los mayores de 31 años estuvo compuesto por once personas que vivieron los momentos de prosperidad del país vecino y conocen distintas migraciones en América Latina. El grupo de los jóvenes entre 18 y 30 años estuvo compuesto por nueve personas, cuyo conocimiento de Venezuela se circunscribe, en esencia, a la situación actual y a la llegada masiva de venezolanos a Colombia, con las consecuencias que está generando. En las dos sesiones, a manera de experimento social, se creó un grupo en WhatsApp para poder enviar los memes seleccionados de forma sincrónica a los participantes y observar las reacciones de cada uno al recibirlos. Luego se realizaron preguntas para establecer sus reacciones y opiniones sobre los memes, sobre los migrantes y sobre Venezuela.

Los memes seleccionados fueron ocho y (como ya se anotó) se extrajeron de Facebook, aunque ello no significa que son creados directamente dentro de esta red social. Muchos de ellos se diseñan en portales especializados en producción de memes (Memedroid) y se ponen a circular luego en las redes. Para su análisis, se tomó como referencia la propuesta de Barthes (1986) que parte preguntándose por el sentido de la imagen y qué hay más allá de este. El autor señala que en toda imagen hay tres mensajes. En primer lugar, el lingüístico, que suele ser la sustancia inicial de todo mensaje, incluso cuando es visual

parece ser que, en cuanto a la comunicación de masas, el mensaje lingüístico esté presente en todas las imágenes: bien bajo la forma de titular, texto explicativo, artículo de prensa, diálogo de película, o globo de cómic; esto muestra que no es demasiado exacto hablar de una civilización de la imagen: aún constituimos, y quizá más que nunca, una civilización basada en la escritura, ya que la escritura y la palabra siguen siendo elementos con consistencia en la estructura de la información. (Barthes, 1986, p. 35)

En segundo lugar, un mensaje icónico codificado, que para Barthes (1986) corresponde a la imagen literal o denotada, y un mensaje icónico no codificado, que correspondería a la imagen simbólica o connotada. Sin embargo, Barthes (1986) reconoce que la imagen denotada no es inocente y nunca rompe la dependencia de la connotada, que es cultural y que está traspasada por idiolectos, ideologías y códigos culturales no tematizados directamente en la imagen, sino como trasfondo, como sentido y metasentido. 


\section{Resultados: el rechazo no tan velado al migrante}

Sobre la base de la propuesta de Barthes (1986), se elaboró una matriz para analizar desde el registro visual la denotación y la connotación de las piezas seleccionadas, buscando establecer la relación entre texto e imagen. A continuación, se muestran cinco de los ocho memes analizados (Figuras 1-5).

Figuras 1-5

Memes analizados

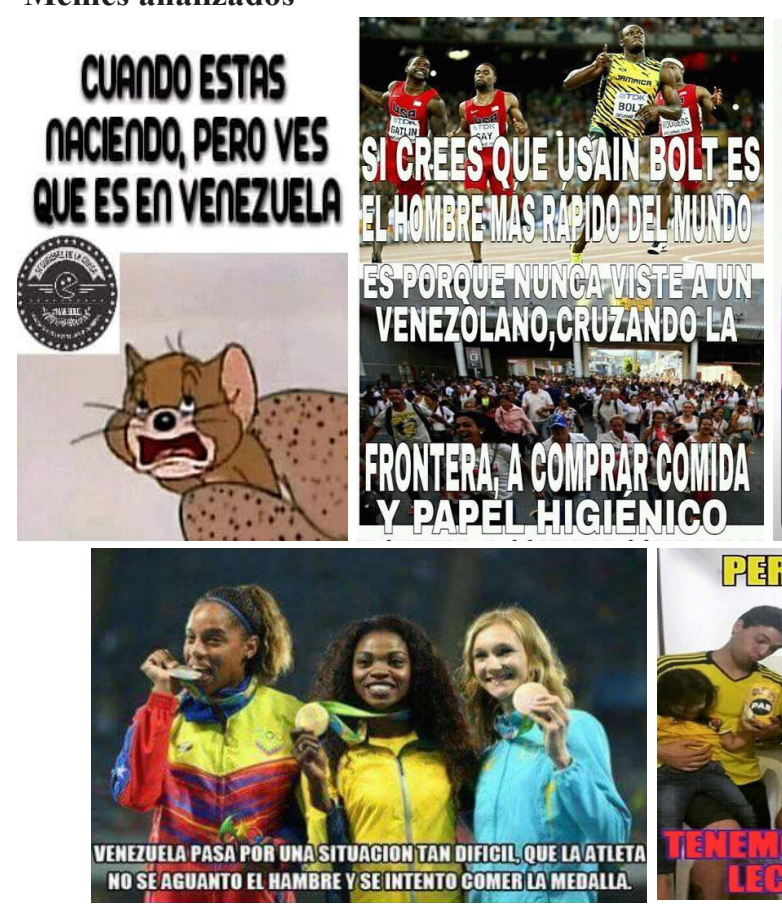

- Mamá conseguí novio y es extranjero.

- La felicito mija, ¿Y de dónde es

el muchacho?

- De Venezuela.

$-\ldots$

Nota: Imágenes editadas de generadores de memes (memedroid) y que circulan en redes sociales (Twitter, Facebook).

El análisis semiótico realizado permitió establecer cinco tematizaciones de los memes: a) la de Venezuela en general como país; b) la de los triunfos relativizados del venezolano en el ámbito deportivo; c) la de los triunfos del colombiano en lo deportivo, aparentemente más meritorios que los del venezolano; $d$ ) la del venezolano como migrante y e) la del venezolano como residente en Colombia. Basándonos en las matrices de análisis elaboradas, de manera extractada, se resalta de cada uno de los cinco memes lo siguiente en cuanto a sus mensajes denotativo y connotativo, siguiendo la propuesta de Barthes (1986). 
La Figura 1 tematiza a Venezuela y muestra la supuesta emoción negativa del propio venezolano respecto de su país, al tiempo que deja ver la imagen que se tiene en el exterior de Venezuela. Jerry, un ratón de una conocida caricatura, emerge de algo que no se puede ver de manera clara, haciendo cara de desagrado. En la parte superior izquierda hay un sello poco legible. Este meme muestra al ratón aprisionado por algo indefinido, haciendo un gesto negativo, que puede indicar dolor, malestar, decepción o desconsuelo.

La imagen refleja un momento desagradable para el ratón que se evidencia en la expresión del rostro (de desilusión), que contrasta con lo que habitualmente representa el nacimiento de un ser humano, pues en la mayoría de culturas connota alegría. El hecho de nacer, de ver la luz, queda en entredicho, en este caso por ser Venezuela el país donde se ha nacido. Se estructura así un cuestionamiento y una desvalorización del país y de la condición del venezolano, que en otras épocas era motivo de orgullo por la imagen de pujanza y riqueza petrolera a la que se le asociaba.

La Figura 2 nos sitúa en la temática del venezolano como migrante y las razones por las cuales atraviesa la frontera hacia Colombia. La imagen se encuentra dividida en dos partes: en la parte superior una imagen que circuló en medios de comunicación sobre uno de los triunfos del jamaiquino Usain Bolt. En la parte inferior, un grupo nutrido de personas aparece corriendo, luego de traspasar lo que parece ser un puesto de control, un puente. Uno de ellos porta una gorra con la bandera de Venezuela. Cada recuadro va acompañado de un texto y hay tres textos, uno en la parte superior, uno al medio y otro en la parte inferior. El primero reza: "Si crees que Usain Bolt es el hombre más rápido del mundo". El segundo: "Es porque nunca viste a un venezolano cruzando la". Y el tercero: "Frontera, a comprar comida y papel higiénico".

El texto de la Figura 2 es correlacional a dos situaciones, en las que la acción de correr es el común denominador: en la primera imagen, en una competencia deportiva, y en la segunda, en una situación de necesidad de conseguir productos básicos. Podría decirse que la principal metáfora usada en este meme alude a la "velocidad", representada en principio a través del hombre más rápido del mundo, que luego es relativizada al ser comparada con la velocidad de los venezolanos que corren aún más rápido para cruzar la frontera en pos de comida y papel higiénico. El afán por llegar al sitio implica conseguir los productos de los cuales se carece en Venezuela, mientras que Colombia representa el abastecimiento. 
El meme de la Figura 3 pone al venezolano ya en situación de residente en Colombia y lo que su presencia genera a nivel de las interrelaciones sociales. Se observa a Amparo Grisales, famosa actriz colombiana que ha participado como jurado en los últimos años en el reality-show "Yo me llamo", en el que se han vuelto habituales sus expresiones de molestia, rabia y desprecio hacia los participantes y también por las peleas que escenifica con los otros jurados. Tal como lo vemos en la imagen (que corresponde a un pantallazo de tal programa) se observa una expresión de que algo negativo acaba de suceder, al tener su mano en la cabeza y al reflejar rechazo y desaprobación con su mirada. El mensaje lingüístico inicial muestra un diálogo entre una hija y su madre. La hija le cuenta que consiguió novio extranjero y la madre la felicita y le pregunta de dónde es. La hija responde que es venezolano y a renglón seguido aparecen puntos suspensivos. Enseguida encontramos la imagen ya descrita de Amparo Grisales haciendo cara de disgusto, incredulidad y desaprobación.

El meme de la Figura 4 recalca la superioridad del colombiano frente al venezolano, en este caso también en el ámbito deportivo. El colombiano triunfa movido por sus capacidades, mientras que el venezolano, pese a estar movido por sus necesidades, no logra siempre el primer lugar. Se muestra la típica escena de premiación en un podio deportivo, donde los ganadores reciben las respectivas medallas de oro, plata y bronce. En este caso las ganadoras son de tres países distintos: Venezuela, Colombia y Kazajstán. Una de ellas (la atleta venezolana Yulimar Rojas) está mordiendo la medalla, haciendo alusión a un acto tradicional que se realiza para expresar la emoción del buen resultado y también para comprobar el material de las medallas. Las tres atletas se ven muy felices en el podio. La colombiana Caterine Ibargüen aparece en la mitad, pues obtuvo el primer lugar (medalla de oro). A la izquierda está la atleta venezolana, mordiendo la medalla obtenida (plata) y a la derecha la medallista que obtuvo el bronce.

En principio, el meme parece reflejar un momento de alegría y celebración, a partir de la imagen literal o denotada. Pero en el mensaje lingüístico direcciona la interpretación de la imagen hacia la connotación de la situación de escasez por la que pasa el pueblo venezolano y la pone en comparación con la de Colombia: la atleta colombiana sonríe satisfecha por el triunfo obtenido; la venezolana también sonríe, pero, a partir del texto inferior de relevo, su sonrisa no se relaciona con la satisfacción por el triunfo, sino por la oportunidad de 
comer algo y saciar el hambre, en este caso con la medalla. Se relativiza así el logro de la venezolana y se resalta que lo supuestamente logrado no alimenta su palmarés deportivo, sino su cuerpo hambriento. Se establece, por tanto, una relación de "inferioridad" versus "superioridad", entre la venezolana y la colombiana. Y se ridiculiza el puesto alcanzado en la competencia por parte de la venezolana, que ni siquiera fue el primero, sino el segundo.

El meme de la Figura 5 tematiza los logros deportivos de los venezolanos cuando el contrincante es Colombia. Dichos triunfos se relativizan en el meme, pues los venezolanos no cuentan con los bienes básicos para subsistir, lo cual los pone en desventaja frente a los colombianos, quienes supuestamente sí cuentan con esos bienes. Se observa la escena típica de celebración familiar de los colombianos vestidos todos con la camiseta de la selección, el día de partido. Se trata del juego que Colombia perdió ante Venezuela el 14 de junio de 2015, en la Copa América celebrada en Chile. Todos tienen en sus manos productos de primera necesidad, como papel higiénico, harina y otros. Los rostros están sonrientes. El meme pone en contraste la tristeza de la pérdida del partido con la alegría de tener qué comer, lo que, por antagonismo, sugiere que, por más que Venezuela haya ganado el partido, no cuenta con las condiciones de vida de los colombianos. El meme usa la metáfora del bienestar representado en la comida, lo cual es un motivo de alegría mayor al del triunfo futbolístico.

Para los colombianos, siempre ha sido deseable relacionarse con un extranjero. Al respecto, Aponte (2010) señala que

lo extranjero es un elemento dominante al cual se le continúa rindiendo veneración, en el contexto actual, y que la colombianidad se sigue construyendo desde los parámetros señalados por las grandes potencias, lo que quiere decir que, para ser más auténticos, más hay que asemejarse a lo extraño y ajeno al ser colombiano, y construirse a partir de elementos que no resultan naturales. (p. 182)

Ello explica la tradicional pleitesía que se les rinde a los foráneos, a los que se considera mejor que a los nacionales y en los que se ve la posibilidad de mejora de las condiciones de vida o de posición social. En el imaginario popular, el extranjero es sinónimo de riqueza, estatus, prestigio, etc. Por eso, conseguir un novio extranjero es algo digno de resaltarse y de lo cual sentirse orgulloso. 
Pero, en las actuales circunstancias, si ese extranjero es un venezolano, no resulta ser algo deseable. El meme acude al imaginario de que el venezolano, en vez de aportar, va a restar, dada su situación de pobreza y marginalidad como migrante.

Los resultados de las encuestas permiten establecer que, en efecto, la migración de venezolanos es vista negativamente en un alto porcentaje, tal como la representan los memes. Un $98,5 \%$ de las 65 personas encuestadas considera que la migración venezolana ha afectado a Colombia de forma negativa en gran medida. Y el ámbito en el que los encuestados identifican la mayor afectación es la seguridad, con un 44,6\%. En segundo lugar, el empleo, con un $30,8 \%$ y en tercer lugar la salud, con $10,8 \%$. Este último hace referencia a la disponibilidad de recursos para la salud y el acceso a los servicios asociados a ella.

Por su parte, los participantes de los dos grupos focales evidenciaron una visión negativa del Venezuela, ya que al hacer mención de la difícil situación que está viviendo ese país, recurrieron siempre a términos como "pobreza", "catástrofe" y "crisis". Sin embargo, no desconocieron que Colombia también enfrenta una realidad compleja.

A través del deporte, los memes reflejaron un escenario de competencia entre el venezolano y el colombiano que, como ya señalamos, intenta saldarse a favor del colombiano. Sin embargo, en el plano laboral la competencia no siempre se salda a favor del colombiano. En efecto, el 76,9\% de los encuestados cree que muchos venezolanos cuentan con la formación y las habilidades para competir en el mercado laboral y el $89,2 \%$ opina que la competencia entre el colombiano y el venezolano es desfavorable para el primero, pues el venezolano acepta una remuneración menor, con lo cual muchos empresarios optan por contratar esa mano de obra más barata. Además, quienes tienen un nivel alto de formación en su mayoría son migrantes legales.

En los escenarios de la economía informal, la principal percepción de los encuestados apunta, en un $43,1 \%$, a que los venezolanos se han tomado ese tipo de economía y han desplazado al colombiano, seguida, con un $27,7 \%$, por la percepción de que son los colombianos los que han sacado partido de los venezolanos, poniéndolos a trabajar bajo sus órdenes. De cualquier forma, las actividades de economía informal más afectadas son, según los encuestados, 
las ventas en transporte público (43,1\%), las ventas ambulantes $(29,2 \%)$ y la mendicidad (27,7\%). El venezolano que trabaja en la informalidad es asociado con la inmigración ilegal.

Los participantes en el grupo focal de los mayores de 31 años consideraron que hay un tema de egos entre los países que no se ha superado, un resentimiento latente de los colombianos hacia los venezolanos, que es reflejado a través de expresiones como los memes. El segundo grupo focal compuesto por menores de 30 años considera que "los memes siempre nos ponen en una situación de superioridad con respecto al venezolano, ya que así se sienten los colombianos". Ambos grupos coinciden en que muchas de las imágenes se elaboran utilizando hechos deportivos, porque estos permiten exaltar emotividades que a veces pasan por alto la realidad de fondo de los dos países.

La mayoría de los encuestados y de los participantes en los dos grupos focales coincidieron en que la migración venezolana es un fenómeno que está impactando de manera negativa al país. Los aspectos en los cuales los colombianos lo han sentido más son la seguridad, el empleo y la salud. A pesar de que se trata de tres problemáticas que siempre han estado presentes en la realidad colombiana, la migración las ha incrementado. En el caso de la inseguridad, esta se ha traducido, según los participantes en el grupo focal, en más robos, asesinatos, fleteos y pandillismo. Así lo revelan resultados de las encuestas, tales como que el 78,5\% de los participantes asocia la migración venezolana con el aumento de la inseguridad, a través de actividades y delitos como los asaltos (45,5\%), el fleteo (14,5\%), el pandillismo $(9,1 \%)$, los asesinatos $(5,5 \%)$, la venta de droga $(3,6 \%)$ y todas las anteriores $(49,1 \%)$.

Con relación al migrante venezolano, el grupo focal de personas mayores de 31 años lo visualiza fundamentalmente como personas jóvenes, que llegaron a Colombia caminando, que vienen porque su moneda no vale nada y es mejor ganar dinero aquí y enviarlo a Venezuela. Asimismo, coinciden en considerar que son personas que traen enfermedades costosas que agudizan la crisis en el sistema de salud de un país como Colombia, en el que hay sectores poblacionales que no tienen fácil acceso a la salud y muchas veces el venezolano logra más atención que el mismo colombiano. En el segundo grupo focal de personas menores de 30 años, muchos mencionaron reiteradamente que han tenido experiencias negativas con los venezolanos, aunque, según ellos, hay que evitar las generalizaciones y estigmatizaciones. 
En cuanto a los memes, el 40,6\% de los encuestados considera que han fomentado la xenofobia y solo el $17,2 \%$ cree que han propiciado la solidaridad. Un 92,3\% afirma no haber compartido esta clase de mensajes y un 7,7\%, sí. Por su parte, los dos grupos focales manifestaron "tristeza" hacia la burla del migrante y sugieren que los autores de los memes deberían utilizar su tiempo en otras actividades. Califican los memes como "denigrantes" y "grotescos" y lamentan que se han vuelto parte del cotidiano. Reconocen que la sociedad se burla de las vulnerabilidades de los otros y que (en vista de que parece ser inevitable la existencia de estos mensajes) es decisión de cada cual lo que se haga con ellos. Sin embargo, en uno y otro grupo focal hubo personas que aceptaron haberlos recibido y reenviado en ocasiones, porque les han parecido graciosos y se han reído mucho, sin pensar en la connotación que puedan tener. Solo unas pocas personas del grupo focal de menores de 30 años reconocieron haber realizado este tipo de memes.

En los grupos focales, algunos afirmaron que la migración venezolana ha afectado la identidad colombiana: "Ya no sabemos si somos más colombianos o venezolanos". Las labores más afectadas de la economía informal por la migración venezolana, según los grupos focales, han sido las relacionadas con "restaurantes", "mensajería” y "prostitución". Son reiteradas, además, las manifestaciones de inconformidad y saturación por la presencia masiva de venezolanos en ventas ambulantes, ventas en transporte público y mendicidad.

Todo lo anterior muestra (con relación a la dinámica de interculturalidad) que, pese a la semejanza cultural entre el colombiano y el migrante, el proceso no está exento de conflictos. Aquí los inmigrantes venezolanos representan los temores clásicos que se generan en la mayoría de los procesos migratorios en el mundo: xenofobia y desestabilización de la estructura del Estado, sobre todo en aspectos como empleo, salud y seguridad. La diferencia con Colombia radica, entre otros aspectos, en que gran parte de los países receptores de población migrante han experimentado en su cotidiano la experiencia multicultural, vista esta como el tránsito y presencia constante de personas con visiones y apropiaciones del mundo diferentes a las del territorio al que se llega, mientras que Colombia no exhibe una experiencia profunda y continua en ese sentido a lo largo de su historia.

Esta experiencia es nueva para los colombianos, quienes, además, han estado expuestos de una manera constante a diversas narrativas asociadas a 
la violencia, que pueden haber impregnado su visión frente a lo nuevo o lo desconocido, lo que de cierta manera encarna el inmigrante, y más cuando de forma masiva e inesperada este irrumpe en su territorio, que hasta hace poco resultaba poco atractivo para foráneos.

Afirmar que en una sociedad se presentan dinámicas de interculturalidad presupone que esta ha atravesado por procesos en mayor o menor escala conflictivos, ocasionados por la existencia de una diferencia. La migración enfrenta a la sociedad colombiana con esa diferencia, que puede terminar alimentando el miedo, el cual es un factor utilizado por algunos actores como una estrategia de control social en diferentes contextos, especialmente el político y el de seguridad, que se evalúan como "amenazados" por la presencia del migrante, dificultando así el proceso de integración intercultural.

Una parte del grupo focal de los mayores de 31 años considera que los memes no tienen una intención de superioridad, pero paradójicamente ven en ellos un "revanchismo macabro", producto de una lucha de egos entre colombianos y venezolanos. Ese revanchismo se debe a un cierto resentimiento de los colombianos que conocieron la Venezuela de otras épocas, como la de la bonanza petrolera de los años de 1970, cuando los venezolanos se creían superiores, rayando en la petulancia, según el sentir de algunos participantes en el grupo focal. Otros, por su parte, consideran que tal vez los memes son realizados por jóvenes que desconocen otros momentos de la historia venezolana y no tienen ningún referente de que el vecino país haya sido próspero. Contrario a esta postura, la mayoría de los jóvenes consideran que los memes siempre nos ponen en una situación de superioridad con respecto al venezolano, lo cual se evidencia en los enunciados de estos y en su “viralización”. Si la gente los rechazara, no tendrían el impacto que tienen ni perdurarían cierto tiempo, pues muchos están desactualizados, pero siguen circulando en redes sociales. Casi todos coinciden en la situación difícil de ambos países. Sin embargo, cuando se hace referencia a Venezuela, resaltan que nadie quiere ir allá en este momento y usan expresiones de pesar con los venezolanos que están llegando.

\section{Discusión}

Los estudios migratorios en el siglo XXI han cambiado sus líneas de interés: ya no focalizan tanto los problemas culturales generados en las naciones que 
recibieron o se formaron por continuas olas migratorias, tales como las que se dieron en el siglo XX durante la Guerra Civil Española, la Segunda Guerra Mundial o el éxodo de latinos a Estados Unidos, sino que el nuevo énfasis está puesto en la visualización de las migraciones como una crisis. El caso, principalmente en Grecia e Italia, del millón y medio de refugiados sirios en 2015 es ilustrativo de esta nueva manera de ver las migraciones. Por un lado, los refugiados vivieron toda una odisea para atravesar los Balcanes y llegar a Alemania y, por otro, los Estados europeos por los que pasaron los migrantes se vieron sobrepasados en su capacidad de respuesta frente a esa problemática.

Pero esa no fue la única crisis: los migrantes africanos subsaharianos también han venido retando la capacidad de países como España y Marruecos para atenderlos en los asentamientos creados para ellos. Andersson (citado en Abdelazziz \& Fernández, 2019) sostiene que "hay una importante 'crisis' en las fronteras del Mediterráneo donde la presión sobre algunas puertas de entrada no hace que cese la voluntad de paso, sino que desplaza a los emigrantes hacia otras direcciones" (p. 41). Los campamentos para migrantes, mayoritariamente latinoamericanos, en la frontera con los Estados Unidos, son otro ejemplo de cómo los estudios se han ido orientando hacia el campo de los derechos humanos y la política internacional, pero la mayoría con el común denominador de la xenofobia como telón de fondo generada por estos flujos.

En Colombia, los ecosistemas mediáticos del siglo XXI (escenarios donde los usuarios no solo se informan, sino que participan y, a la vez, se convierten en emisores de sus posiciones sobre la migración) se han convertido en objeto de estudio para proyectos como el "Barómetro de Xenofobia",

un proyecto elaborado por "El Derecho a No Obedecer", en conjunto con la Corporación Otraparte, el Observatorio de Migraciones de la Universidad Externado de Colombia y el Observatorio sobre Racismo, Xenofobia y Odio, proyecto de la Fundación Interpreta de Chile, la Friedrich-Ebert-Stiftung en Colombia y Save The Children. (Carrasco, 2020)

Los resultados de los análisis desarrollados por el "Barómetro de Xenofobia" guardan bastante simetría con lo que reflejaron las encuestas de la presente investigación, cuyos participantes señalaron, en un 44,6\%, que la seguridad 
es el principal ámbito en el que la migración ha afectado a Colombia. Basados en 92,000 mensajes analizados en redes sociales, categorizados en "salud", "educación", "crimen” y "xenofobia", el Barómetro "llegó a la conclusión de que el tema de la criminalidad es el mayor impulsor en las conversaciones relacionadas con la población migrante, acompañadas de mensajes xenófobos" (Carrasco, 2020).

En efecto, el 56\% de los mensajes sobre migración categorizados giraron en torno al tema del crimen. Es decir, los usuarios de las redes sociales suelen asociar de diversas formas la criminalidad con el migrante venezolano, pese a que no hay evidencia de que la criminalidad en Colombia haya aumentado ni que ese hipotético aumento sea atribuible a la migración (Carrasco, 2020). Los mensajes de las redes (en especial los memes) constituyen hoy un reto para el análisis de la cultura actual, en la que esta nueva especie de "collage" se hace y reproduce con una velocidad sin precedentes y cuyo poder

radica en la formalización de una idea. En un diseño. En la selección de ciertas imágenes y su combinación con ciertas palabras. Es importante diseccionar su estética para entender su capacidad de penetración en nuestras mentes, que transforman en agentes de contagio. ¿Por qué esa artesanía tan precaria consigue secuestrar nuestra atención durante tres segundos y que pulsemos el botón de "compartir"? Porque apela a la dimensión más exportable de nosotros mismos. (Carrión, 2020)

Para algunos analistas, a la par con su potencial político, el meme tiene potencial estético, lo cual es un aspecto poco estudiado de este tipo de expresiones.

Los memes constituyen un auténtico telón de fondo de nuestra época. Dice la investigadora y activista An Xiao Mina en Memes to Movements que son el "street art" de Internet. Si el rap o el grafiti dieron expresión artística al malestar social de los años ochenta, muchos de los memes que se producen y consumen expresan el virtual del siglo XXI. Aunque haya sido convertido en un arma propagandística sobre todo por la derecha y la extrema derecha, su difusión ha alimentado la indignación y las protestas tanto de los aficionados al deporte como de los fans de series de televisión, tanto de los movimientos progresistas como de los conservadores. A todos nos une, para bien y sobre todo para mal, el poder imantador de los memes. (Carrión, 2020) 
Dada la índole expresiva, compositiva y reproductiva del meme, también tiene potencial, como ha quedado evidenciado en la presente investigación y en los estudios del "Barómetro de Xenofobia" de Colombia para alentar odios y estigmatizaciones, a través de la burla, la ridiculización, la parodia.

La investigación aquí presentada buscó entender las representaciones e imaginarios sobre la migración de venezolanos a Colombia a través de los memes que circulan en redes sociales, para contrastarlas con encuestas en línea y las opiniones de dos grupos de usuarios diferenciados por edades, lo que permitió también establecer que el consumo de estos mensajes puede usarse como una forma de disimular lo que sucede en Colombia, pues impide ver problemáticas propias.

Esta investigación coincide con el actual interés por rastrear la "forma" como "sentimientos", en este caso de xenofobia y superioridad (que circula en redes sociales) donde los memes favorecen una lectura de la realidad colombiana en estos términos (a nivel social y económico) respecto de la realidad venezolana, pero tal superioridad para la mayoría de los encuestados y entrevistados es aparente, y para otros (si es que existe) no habilita burlarse de los venezolanos. Por lo tanto, consideran que nadie se debería reír de la situación por la que están pasando. Sin embargo, en especial en el grupo de jóvenes, esta fue la primera reacción ante los memes, lo que posteriormente, se convirtió en una oportunidad de reflexión para todos, de cuestionamientos frente a la situación en Venezuela y sobre muchas de las problemáticas que se comparten con Colombia. Al respecto,

si bien millones de personas se pueden llegar a reír, simultáneamente, por el mismo meme, también grandes masas de población pueden decidir cambiar sus percepciones sobre la inmigración, un partido político o la violencia de género tras recibir esas viñetas de opinión, esas píldoras efímeras, esos chistes textovisuales. (Carrión, 2020)

Son varios los estudios en países vecinos que, en una tendencia cualitativa, analizan percepciones sobre los flujos migratorios, y cuyos resultados son coincidentes. Uno de estos es el de Cuevas-Calderón (2018), el cual evidencia la situación de vulnerabilidad en la que llegan los migrantes venezolanos al Perú y muestra la dificultad que existe en los países de la región (incluido Colombia) para atender la situación y lo complejo que ha sido recibir a los 
migrantes y tratar las problemáticas asociadas a ellos. Estas investigaciones perfilan el interés por expandir el horizonte de análisis, más allá de la focalización del fenómeno migratorio en sí.

En ese sentido, la presente investigación propone abrir una línea de estudio que ponga en relación el tema de la migración, las redes sociales, los mensajes que circulan a través de ellas y la identidad. En el caso de los memes objeto de esta investigación, el sentimiento de desesperanza que transmiten es evidente en relación con la situación actual de Venezuela, pero la aparente superioridad del colombiano sobre el venezolano que tematizan no está exenta de contradicciones y ameritan muchos estudios con enfoques multidisciplinarios. Ese sentimiento de desesperanza, aunque de forma menos denotada, también es detectable con respecto a la situación de Colombia.

Pese al potencial estético del meme, los aquí analizados resultan ser reduccionistas, simplistas y facilistas desde un punto de vista comunicativo. Así lo manifestaron los entrevistados, quienes consideraron que otros formatos humorísticos como las caricaturas publicadas, por ejemplo, en los periódicos y revistas tradicionales son más incisivas y creativas, y resaltaron también que los memes muestran aspectos propios de la sociedad colombiana, como el clasismo, la exclusión y su alta emotividad.

Aunque los memes han estado al servicio de todo tipo de propósitos, algunos analistas consideran que han sido más aprovechados para alentar sentimientos negativos que positivos, posturas más radicales que flexibles, más monolíticas que diversas, como en el caso de los memes sobre los migrantes venezolanos en Colombia.

No podemos permitir que sean un monopolio de la ultraderecha, un vehículo para la transmisión de racismo, homofobia, machismo o teorías de la conspiración. Los medios de comunicación más responsables y serios y los proyectos políticos progresistas deberían poner en circulación sus propios memes. Y todos nosotros tendríamos que reflexionar críticamente durante unos segundos sobre el contenido que hemos recibido en nuestro teléfono antes de compartirlo. O, mejor aún, de preferir no hacerlo. (Carrión, 2020) 
Desde el punto de vista del análisis del discurso, no deja de llamar la atención que, en la producción narrativa, los entrevistados menores de 30 años (cuando se refieren o enuncian la situación de Venezuela) usan expresiones como "catástrofe" o "crisis" y la asocian con "opresión", "pobreza" y "desesperación". En su mayoría, no se refieren a otras épocas distintas a la actualidad de Venezuela. Parecen no estar de acuerdo con la corrosividad y la burla descarnada articuladas en los memes, pero sus imaginarios sobre el venezolano y la situación de Venezuela no se alejan de lo que proponen los memes en sus estructuras más profundas. Entre tanto, el grupo conformado por personas mayores de 31 años hizo referencia a períodos, situaciones y personajes (reinas de belleza) que evocaban mejores épocas de Venezuela, con palabras como "bonanza", "opulencia" y "riqueza", haciendo referencia a momentos históricos distintos, lo que permite observar contrastes y, por ende, elaboraciones conceptuales e imaginarias diferentes, pero sin que ello implique una visión positiva acerca de la Venezuela de hoy.

De tal forma que la visión del grupo focal conformado por menores de 30 años es menos matizada, menos contrastada, pues "Venezuela" y el "venezolano" son sólo lo que son hoy, mientras que la visión del grupo de mayores de 31 años posee la intensidad del contraste entre el pasado y el presente. En concordancia con lo antes señalado, Alvarado \& Pino (2018) narran tal contraste, pues, a mediados del siglo XX, Venezuela fue un destino para los migrantes que aprovecharon la bonanza económica generada por el petróleo.

Finalmente, otro aspecto para destacar es la importancia de la información de índole cualitativa sobre problemáticas sociales como los medios y la migración, obtenida a través de las partes involucradas, debido a que resulta más dinámica y reveladora que la información obtenida por vías investigativas de orden exclusivamente cuantitativo. El estudio de un fenómeno como la migración debe posibilitar conocimiento valioso tanto para la población migrante como para la nativa, a la hora de enfrentarse a fenómenos nuevos, especialmente aquellos que involucran la presencia masiva en su cotidiano de personas con visiones y necesidades diferentes a las de ellos. 


\section{Conclusiones}

Las redes sociales y los memes son considerados un espacio de expresión de gran importancia en la actualidad que posibilita, en este caso, exponer las experiencias que han tenido los colombianos, derivadas de la presencia de los migrantes venezolanos y los imaginarios generados frente a los mismos. Su circulación y divulgación permiten acercarse a la interpretación y comprensión de este fenómeno social por convertirse en manifestaciones de la opinión pública.

En este sentido, una de las primeras conclusiones de la investigación para resaltar hace referencia a un posible camino metodológico detectado para acercarse al conocimiento de la opinión pública contenida en piezas de circulación como los "memes", que dan cuenta de los diversos puntos de vista y discursos contenidos en la cognición social y en la cultura. Aspecto importante, dada la relevancia que asumen las redes sociales como escenario estratégico de expresión política y la triangulación metodológica propuesta (análisis de los memes, encuesta y grupos de discusión) para su indagación.

Las transformaciones en los medios para comunicarnos han determinado cambios en los códigos y lenguajes, lo que conlleva innovaciones en la forma de ver e interpretar el mundo. Por lo tanto, los contenidos que presentan los memes dejan ver las prelaciones culturales, estableciendo en la selección de temas las prioridades discursivas que muestran rasgos culturales y aspectos centrales de la agenda pública.

La producción de sentido sobre la coyuntura sociopolítica en Colombia, a partir de la llegada masiva de migrantes, se refleja en las redes sociales que se transforman hoy en expresión de ideas diversas en tensión por la construcción de sentido. De allí la pertinencia de comprender sus nuevos códigos y lenguajes. De forma específica, se establece que los memes se han utilizado para propiciar formas de xenofobia a través del chiste, la burla o el sarcasmo, atribuyendo a los colombianos una situación o estado de aparente superioridad. Superioridad contradictoria, en la medida en que se convierte al mismo tiempo en evidencia de un imaginario sobre los propios miedos ante la crisis, testimonio de preocupaciones comunes alrededor de aspectos como la alimentación, el empleo, la seguridad, la salud o los servicios básicos, temáticas presentes en los memes, indagados en la encuesta y profundizados en los grupos de discusión. 
Es interesante observar, desde un punto de vista comunicativo, lo estratégico que resulta el humor en la producción de sentido alrededor de temas absolutamente trascendentales en la construcción de opinión pública. El contenido breve, emocional (que usa la metáfora, el sarcasmo y la ironía como recursos retóricos básicos) se convierte en el lenguaje que encubre de forma simplista los contenidos ideológicos que movilizan la política, aspecto que denota un vaciamiento de la argumentación pública. Primero está la risa fácil y después se reflexiona para sentirse crítico y consciente. Esa pareciera ser la forma que toman las tácticas de persuasión en la construcción de consenso social, con la diferencia de que todos somos prosumidores e interactores en la producción y propagación de las formas de control y manipulación, con un riesgo agregado: se intenta confundir la participación social con la facilidad de un clic y un "me gusta".

El meme destaca todas las desgracias por las que está pasando Venezuela e incluye expresiones hostiles, que parecen constituirse en una revancha, basada en la discriminación que sufrieron los migrantes colombianos en Venezuela décadas atrás. Así lo expresaron sobre todo los integrantes del grupo focal de mayores de 31 años.

Como se observa en la circulación de memes, el usuario pasa instantáneamente a jugar el papel de prosumidor o interactor, sirviendo de conexión o puente con la posibilidad de transformar los contenidos recibidos, reelaborando significados, produciendo nuevos o simplemente reenviando o comentando. De esa forma, contribuye y participa (así sea ingenuamente) en la propagación y divulgación de ideas e ideologías, inspiradas en tensiones, como las que se han desarrollado entre los gobiernos de Colombia y Venezuela desde la primera década del presente siglo en razón de sus enfrentados modelos sociopolíticos, y que, con distintas intensidades, se han mantenido hasta hoy. Tales tensiones e ideologías han influenciado la manera cómo el inmigrante es representado tanto en los medios de comunicación tradicionales como en los "nuevos" (incluidos los memes), lo cual ha sido determinante en la elaboración de la visión que los colombianos tienen sobre los venezolanos, la cual va desde la compasión, hasta la percepción de que son una amenaza. Son visiones e imaginarios que median las interacciones sociales y pueden facilitar o entorpecer los inevitables procesos de integración social presentes en el encuentro e intercambio cultural de toda dinámica migratoria. 
El ecosistema mediático que se vive en la actualidad ha generado cambios en la circulación y apropiación de la información. La sobresaturación de información que existe en las redes y el bombardeo a cada instante de contenidos de todo tipo impiden que en muchas ocasiones se asuma su uso de forma razonada para elaborar una postura crítica de cara al consumo mediático. Es pertinente hacer un llamado al uso reflexivo y responsable de los contenidos mediáticos a los cuales se ven expuestos los usuarios de las redes, para no convertirse en puentes pasivos o en transmisores inconscientes de formas de representar o imaginar la realidad que obstaculicen el logro de la interculturalidad y actúen en detrimento de la dignidad de otras personas.

\section{Fuentes consultadas}

Abdelaziz, S., \& Fernández, M. (2019). Migrantes Subsaharianos en sus primeros asentamientos pre y post frontera española. Aposta. Revista de Ciencias Sociales, 80, 27-43. http://www.apostadigital.com/revistav3/ hemeroteca/siham.pdf

Althusser, L. (1988). Ideología y aparatos ideológicos del Estado. Nueva Visión.

Alvarado, M., \& Pino, T. (2018). Rituales migratorios 2.0. Imagen, emoción y diáspora venezolana. Archivos de la filmoteca: Revista de estudios históricos sobre la imagen, 75, 225-240

Aponte, L. (2010). Identidad colombiana en Fernando González Ochoa. Franciscanum, 52(154), 167-196. https://doi.org/10.21500/01201468.947

Barthes, R. (1986). Lo obvio y lo obtuso. Imágenes, gestos, voces. Paidós.

Baudrillard, J. (2000). El crimen perfecto. Editorial Anagrama.

Carrasco, D. (2020, Agosto 26). Barómetro de xenofobia: De qué se habla en Colombia sobre los venezolanos migrantes. https://elpitazo.net/ migracion/barometro-de-xenofobia-de-que-se-habla-en-colombia-sobre-los-venezolanos-migrantes 
Carrión, J. (2020, Agosto 30). Política y estética del meme. The New York Times. https://www.nytimes.com/es/2020/08/30/espanol/opinion/quees-un-meme-internet.html

Castoriadis, C. (2007). La institución imaginaria de la sociedad. Fábula Tusquets.

Christakis, N., \& Fowler, J. (2010). Conectados. El sorprendente poder de las redes sociales y cómo nos afectan. Santillana.

Cuevas-Calderón, E. (2018). Reconfiguración social: entre la migración y la percepción inseguridad en Lima. URVIO, Revista Latinoamericana de Estudios de Seguridad, 23, pp. 73-90. http://dx.doi.org/10.17141/ urvio.23.2018.3553

Dawkins, R. (1989). El gen egoísta, las bases biológicas de la conducta. Horus.

Dittus, R. (2006). El imaginario social y su aporte a la teoría de la comunicación: seis argumentos para debatir. Universidad Católica de la Santísima Concepción.

Durand, G. (1979). Las estructuras antropológicas de lo imaginario. Taurus.

FEDESARROLLO. (2018). Informe mensual del mercado laboral. Migración venezolana a Colombia. Octubre 2018. https://www.fedesarro1lo.org.co/sites/default/files/iml-octubre_2018-web.pdf

Lenin, V. (1997). El Estado y la revolución. Fundación Federico Engels.

Lull, J., \& Neiva, E. (2011). Hacia una nueva conceptualización evolutiva de la comunicación "cultural". Comunicar, 36(18), 25-34. https://doi. org/10.3916/C36-2011-02-02

Maffesoli, M. (1987). O Conhecimento do Quotidiano. Vega.

Martín Barbero, J. (1987). De los medios a las mediaciones. Comunicación, cultura y hegemonía. Gustavo Gili. 
Marx, K. (2012). Escritos sobre materialismo histórico. Alianza Editorial.

Ministerio de Relaciones Exteriores de Colombia. (2020, Agosto 6). Para finales del mes de mayo, el 3\% del total de venezolanos que se encontraban en Colombia al comienzo de la pandemia había regresado a su país y un 2\% más estaría a la espera de poder hacerlo. https://www. migracioncolombia.gov.co/noticias/para-finales-del-mes-de-mayo-el3-del-total-de-venezolanos-que-se-encontraban-en-colombia-al-comienzo-de-la-pandemia-habia-regresado-a-su-pais-y-un-2-mas-estaria-a-la-espera-de-poder-hacerlo

Pineda, E., \& Ávila, K. (2019). Aproximaciones a la migración: Desigualdad, prejuicio y vulnerabilidad. CLIVATGE. Estudis $i$ testimonis sobre el conflicte i el canvi socials, 7, 46-97. https://revistes.ub.edu/index.php/ clivatge/article/view/28596

Shifman, L. (2013). Memes in a Digital World: Reconciling with a Conceptual Troublemaker. Journal of Computer-Mediated Communication, 18(3), 362-377. https://doi.org/10.1111/jcc4.12013

Wiggin, B., \& Bowers, B. (2015). Memes as genre: A structurational analysis of the memescape. New Media \& Society, 17(11), 1-21. https://doi. org/10.1177/1461444814535194 